\title{
Synthesis of ZnS: $\mathrm{Tm}^{3+}$ Nanoparticles by the Polyol Method
}

\author{
Francisco Jesus Rodriguez, Joan Reyes, Dulce Y. Medina, Miguel Angel Barron, Catalina Haro-Perez
}

Ciencias Básicas e Ingeniería, Universidad Autónoma Metropolitana, Mexico City, México

Email: bmma@correo.azc.uam.mx

How to cite this paper: Rodriguez, F.J., Reyes, J., Medina, D.Y., Barron, M.A. and Haro-Perez, C. (2019) Synthesis of ZnS:Tm ${ }^{3+}$ Nanoparticles by the Polyol Method. Open Journal of Applied Sciences, 9, 613-619. https://doi.org/10.4236/ojapps.2019.97049

Received: May 25, 2019

Accepted: July 27, 2019

Published: July 30, 2019

Copyright $\odot 2019$ by author(s) and Scientific Research Publishing Inc. This work is licensed under the Creative Commons Attribution International License (CC BY 4.0).

http://creativecommons.org/licenses/by/4.0/

\section{cc) (i) Open Access}

\begin{abstract}
In this work, the synthesis of undoped and Tm-doped $\mathrm{ZnS}$ nanoparticles is successfully carried out by the polyol method. From XRD analyses, it was confirmed that both types of particles possess the cubic zinc blend structure of the $\mathrm{ZnS}$, and that the structure is not altered by doping. The crystallite size computed by the Scherrer equation is about $9 \pm 1 \mathrm{~nm}$. From photoluminescence analyses, the results show that the excitation spectrum has two excitation peaks at $304 \mathrm{~nm}$ and $356 \mathrm{~nm}$; by exciting at $304 \mathrm{~nm}$, a strong blue emission is observed at $420 \mathrm{~nm}$, while exciting at $356 \mathrm{~nm}$ the characteristic Tm transition ${ }^{1} \mathrm{G}_{4} \rightarrow{ }^{3} \mathrm{H}_{6}$ is observed at $417 \mathrm{~nm}$. By doping with $\mathrm{Tm}$ ions, the emission color changes from pure blue to sky according to the change in CIE coordinates from $x=0.15, y=0.015$ to $x=0.18, y=0.17$, respectively.
\end{abstract}

\section{Keywords}

Luminescence, Zinc Sulfide, Blue Emission

\section{Introduction}

Zinc sulfide $(\mathrm{ZnS})$ is a semiconductor which in the size range of nanoparticles (1 - $100 \mathrm{~nm}$ ), exhibits photoluminescent properties when it is excited by ultraviolet radiation, where the color emission is directed related to the size particle [1]. The unique properties of these nanoparticles, such as photoluminescence and electroluminescence, make these nanoparticles important for many technological applications, for example, light emitting diodes (LEDs), sensors, displays, lasers, solar cells, and for biomedical applications [2] [3] [4] [5].

During the last decade, a special emphasis has been put on the synthesis of high monodispersed semiconducting nanoparticles, with stability for a long period of time, control of the nanocrystal size and morphology [6] [7], which are very important factors to influence the optical properties of $\mathrm{ZnS}$ and their appli- 
cations. Different methods have been reported for the synthesis of $\mathrm{ZnS}$, for example, hydrothermal [8], sol-gel [9], solid state reaction [10] and polyol method [11]. Among them, the polyol method is considered a green synthesis method because no toxic chemicals are used; it only needs a glycol source such as ethylene glycol, polyethylene glycol, glycerol, etc. Besides, in many cases, temperatures below $150^{\circ} \mathrm{C}$ are required in the synthesis, giving as result chemical stability, biocompatibility, and low toxicity homogeneous materials [12].

On the other hand, it can be found that doping $\mathrm{ZnS}$ nanoparticles with other ions, for instance $\mathrm{Mn}^{2+}$, produce a catalysis-assisted CL emission [13]. However, the doping with rare earth trivalent ions is very difficult by conventional methods because the difference in valence number and the higher ionic radius avoids the lanthanide ions enter to the ZnS crystal structure [14], however, the polyol method allows the incorporation of lanthanide ions into the $\mathrm{ZnS}$ structure. In this regard, this article shows the results of the effect of Tm ions on the ZnS nanoparticles, regarding the crystal structure and photoluminescent properties.

\section{Experiment Details}

The synthesis of $\mathrm{Tm}^{3+}$ doped $\mathrm{ZnS}$ nanoparticles was carried out by the polyol method. The precursors: Thulium nitrate $\left(\mathrm{Tm}(\mathrm{NO})_{3}\right)$, Thiourea $\left(\mathrm{NH}_{2} \mathrm{CSNH}_{2}\right)$ and Zinc acetate $\left(\mathrm{Znc}_{4} \mathrm{H}_{6} \mathrm{O}_{4}\right)$ were purchased at Sigma Aldrich. Ethylene glycol and ethanol were used as solvents.

For the synthesis, $3 \mathrm{mmol}$ thiourea and $3 \mathrm{mmol}$ zinc acetate precursors were dissolved in $20 \mathrm{~mL}$ ethylene glycol under vigorous stirring at room temperature for 20 minutes. Then an adequate volume of $\mathrm{Tm}(\mathrm{NO})_{3}$ dissolved in ethanol $\mathrm{C}_{2} \mathrm{H}_{6} \mathrm{O}_{2}$ was added to keep 3 and 5 at \% with respect to $\mathrm{ZnS}$. In addition, an undoped $\mathrm{ZnS}$ sample was synthesized for comparison purposes. After that, the temperature of the solution was increased up to $120^{\circ} \mathrm{C}$ under stirring for $2.5 \mathrm{~h}$. Then, the resulting white precipitate was separated from the final solution and washed with distilled water three times by centrifugation at $4000 \mathrm{rpm}$. Finally, the obtained product was dried in an oven at $80^{\circ} \mathrm{C}$ by $24 \mathrm{~h}$.

The crystal structure of Tm doped $\mathrm{ZnS}$ powders was analyzed by XRD, conducted in reflective mode in a Bruker D8 ADVANCE eco diffractometer with $\mathrm{Cu}$ $\mathrm{Ka}_{1}$ radiation $(\lambda=0.15406 \mathrm{~nm})$, in the range of $10^{\circ}-60^{\circ}$. With the aim to know the powders morphology, it was used a scanning electron microscopy JEM-2200FS model operating at $80 \mathrm{keV}$. For luminescence analysis, excitation and emission spectra were obtained by using a Horiba Jobin-Yvon Flourolog 3 - 22 spectrofluorometer equipped with a $450 \mathrm{~W}$ ozone-free Xe lamp for the steady state mode and a pulsed Xe lamp.

The nanoparticle size was determined by dynamic light scattering by using a Zetasizer Nano ZS90 device (Malvern Instrument) equipped with a He-Ne laser and avalanche photodetectors. The hydrodynamic radius is obtained from acumulant analysis of the intensity correlation function measured at $90^{\circ}$ and the 
reported values are the mean of different measurements performed with different samples.

\section{Results and Discussion}

\subsection{Structural Analyses}

Figure 1 shows the XRD patterns of (a) undoped ZnS and (b) Tm-doped ZnS nanoparticles, respectively. As can be observed, Tm ions do not modify the crystal structure of $\mathrm{ZnS}$. The reflections (111), (220) and (311) can be indexed to the cubic blend ZnS structure according to the JCPDS card No. 05-0566 [15]. From the patterns, the crystallite size was computed by using the Scherrer equation:

$$
D=(0.9 \lambda) / \beta \cos \theta
$$

where $D$ is the average crystallite size, $\mathrm{K}$ is a constant with a value close to unity, $\lambda$ is the X-ray wavelength $(\mathrm{CuK} \alpha=0.15418 \mathrm{~nm}), \beta$ is the Full Width at Half Maximum (FWHM), and $\theta$ is the half diffraction angle of the centroid of the peak 3 . The computed crystallite size was about $9 \pm 1 \mathrm{~nm}$.

Figure 2 shows the SEM images of the ZnS:Tm (5 at. \%), the image reveals agglomerated spherical particles with an average size of $90 \pm 5 \mathrm{~nm}$. The agglomeration of these nanoparticles is due to their high surface energy, and the presence of van der Waals attractive forces.

\subsection{Dynamic Light Scattering Measurements}

The mean hydrodynamic diameter measured by dynamic light scattering is ( 245 $\pm 14) \mathrm{nm}$ for the undoped Zns nanoparticles. For the doped nanoparticles the hydrodynamic diameter increases up to $(280 \pm 18 \mathrm{~nm})$ and $(550 \pm 30 \mathrm{~nm})$ in case of $\mathrm{ZnS}: \operatorname{Tm}$ ( 3 at. \%) and (5 at. \%), respectively. Here, the uncertainty is estimated as the standard error of the mean.

\subsection{Photoluminescence Results}

Figure 3(a) depicts the excitation and emission spectra of the $\mathrm{ZnS}$ nanoparticles.

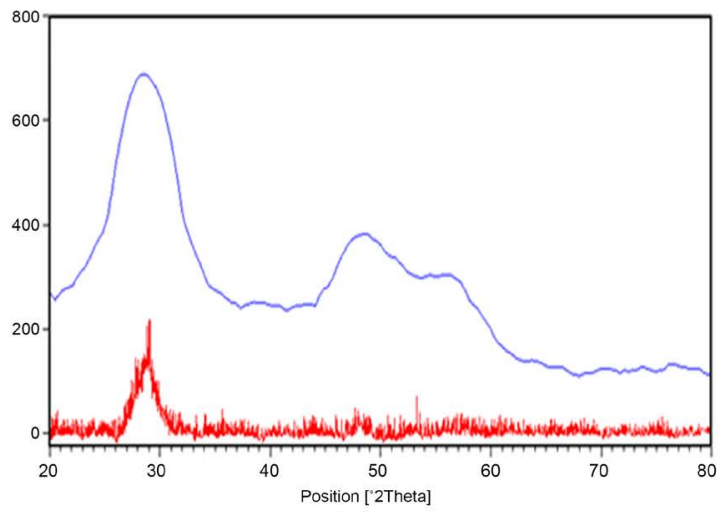

(a)

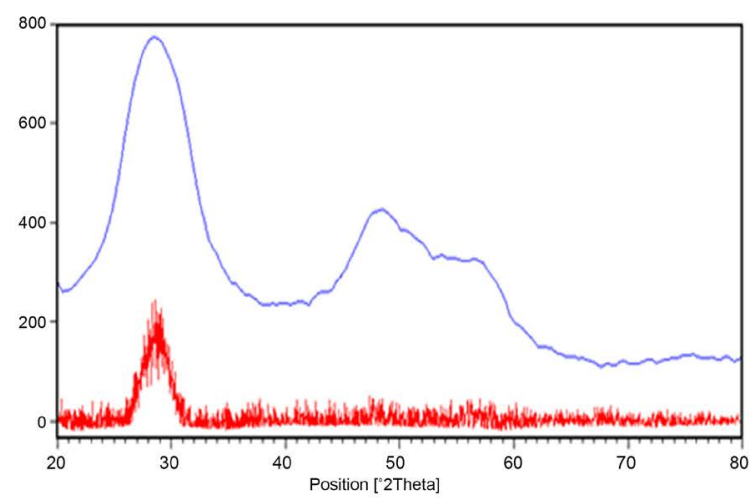

(b)

Figure 1. X-ray diffraction patterns of (a) undoped and (b) ZnS:Tm nanoparticles. 


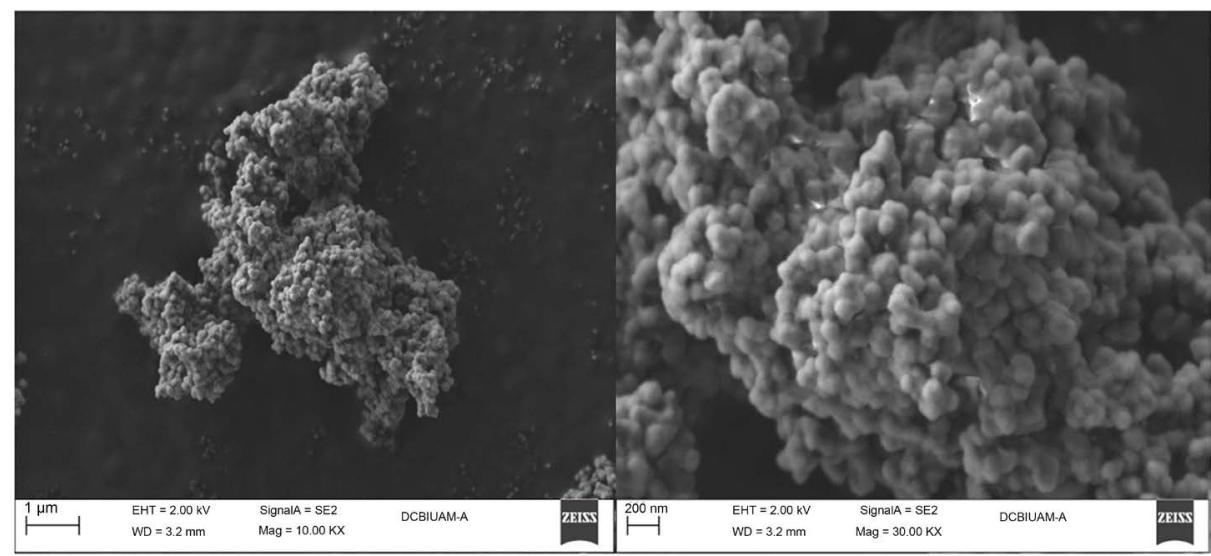

Figure 2. SEM images of ZnS:Tm (5 at. \%) nanoparticles at different magnifications.

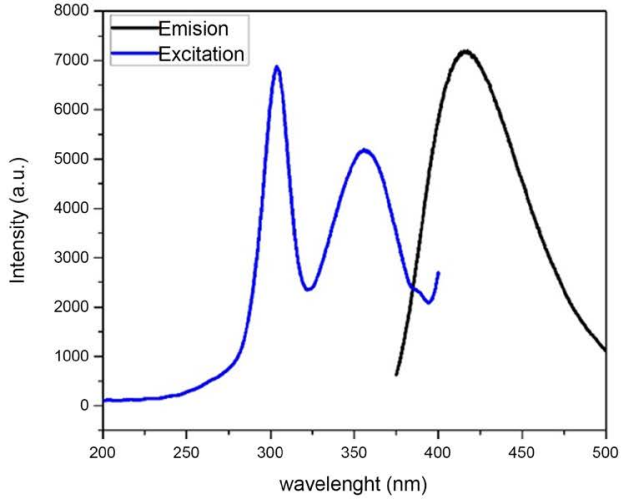

(a)

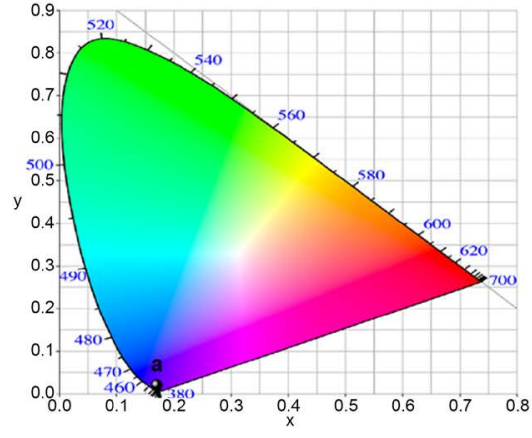

(b)

Figure 3. (a) Excitation and emission spectra of undoped $\mathrm{ZnS}$ nanoparticles; (b) CIE coordinates of the undoped $\mathrm{ZnS}$.

The excitation spectrum (blue line) shows that zinc sulfide has two excitation peaks at 304 and $356 \mathrm{~nm}$. On the other hand, the emission spectra (black line) show a broad blue emission centered at $420 \mathrm{~nm}$ by exiting the sample at $304 \mathrm{~nm}$. From the emission spectra, the CIE coordinates were computed as $x=0.15, y=$ 0.015 . Figure $3(\mathrm{~b})$ displays the highly blue emission in the CIE map.

Figure 4(a) shows the emission spectra of Tm-doped $\mathrm{ZnS}$ QDs at 3 at. \% and 5 at. \% by exciting at $304 \mathrm{~nm}$. As can be seen, these spectra are similar to those obtained for the undoped $\mathrm{ZnS}$ sample, with the difference that the emission intensity is increased due to the higher Tm content (5\%). Besides, by doping with Tm ions, the CIE coordinates (see Figure 4(b)) are shifted slightly to the sky blue color region with the next CIE coordinates: $x=0.15, y=0.055$.

On the other hand, when the samples are excited at $356 \mathrm{~nm}$ (see Figure 5(a)), the luminescent intensity increases and a peak at $417 \mathrm{~nm}$ emerges, corresponding to the electronic transition of $\operatorname{Tm}\left({ }^{1} \mathrm{G}_{4} \rightarrow{ }^{3} \mathrm{H}_{6}\right)$ [16]. Besides, the spectra show a shoulder at $500 \mathrm{~nm}$ which is absent in case of samples that are not doped. This contribution makes the CIE coordinates shift to the green region, obtaining new CIE coordinates about as $x=0.18 y=0.17$ (Figure 5(b)). 


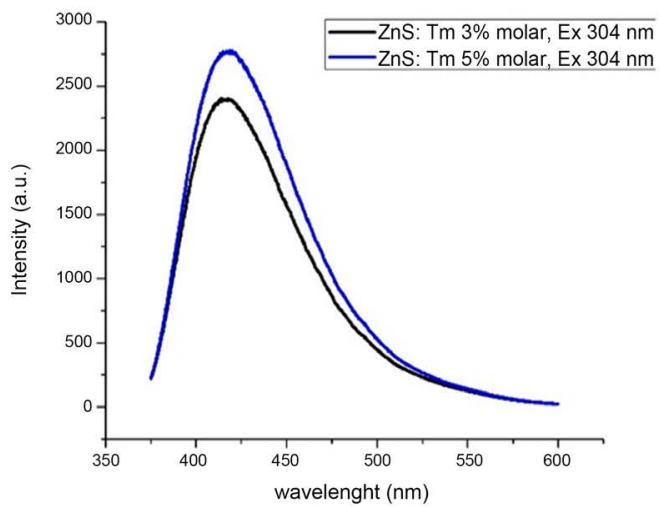

(a)

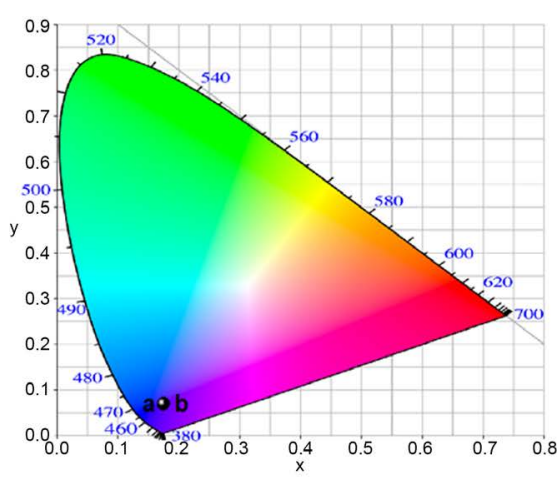

(b)

Figure 4. (a) Emission spectra of the ZnS: $\mathrm{Tm}^{3+} 3$ - 5 at. \%, excited to $304 \mathrm{~nm}$; (b) CIE coordinates of $\mathrm{ZnS}: \mathrm{Tm}^{3+}$.

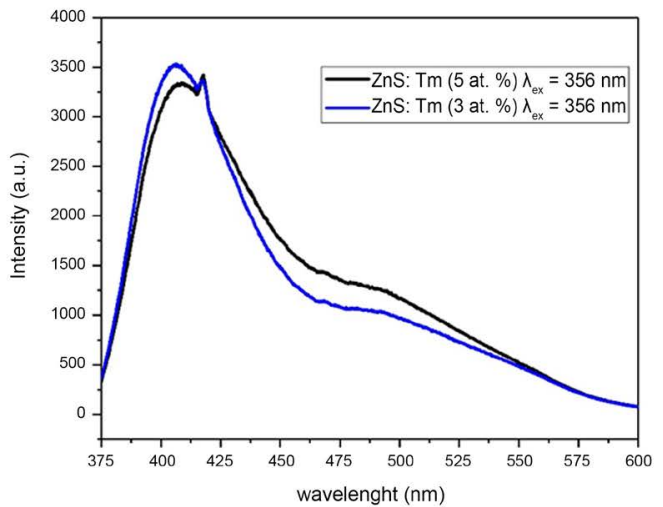

(a)

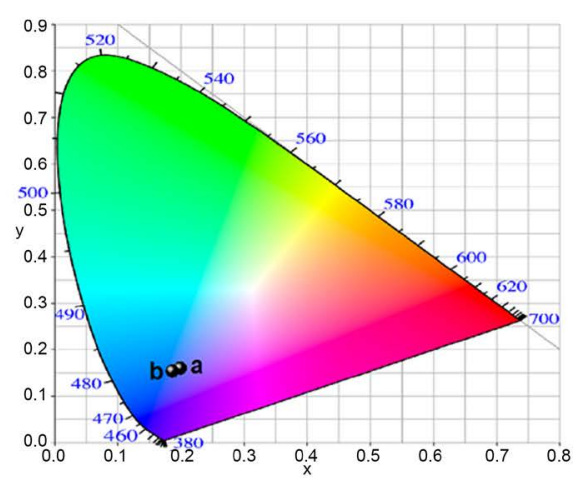

(b)

Figure 5. (a) Emission spectra of the ZnS: $\mathrm{Tm}^{3+} 3$ - 5 at. \%, excited to $354 \mathrm{~nm}$; (b) CIE coordinates of $\mathrm{ZnS}: \mathrm{Tm}^{3+}$.

\section{Conclusion}

Luminescent undoped and Tm-doped $\mathrm{ZnS}$ powders were successfully synthesized by the polyol method, from which crystalline $\mathrm{ZnS}$ structure indexed to the pure blend cubic form was obtained. The light emission was dependent on the Tm content and the excitation wavelength. When the sample is not doped, a broad blue emission centered at $420 \mathrm{~nm}$ was observed by exciting at $304 \mathrm{~nm}$. By doping the samples at 3 and 5 at. \% with Tm ions and exciting at $304 \mathrm{~nm}$, quite similar emission spectra of the undoped sample are obtained. However, by exciting at $354 \mathrm{~nm}$, the typical $\mathrm{Tm}^{3+}$ transition ${ }^{1} \mathrm{G}_{4} \rightarrow{ }^{3} \mathrm{H}_{6}$ was identified at $417 \mathrm{~nm}$ and this peak is accompanied by a shoulder centered at $500 \mathrm{~nm}$ which changes the color emission according to the computed chromatic coordinates as $X=0.15$, $y=0.055$ and $x=0.18, y=0.17$ for the sample doped at 5 at. \% Tm excited at 304 and $354 \mathrm{~nm}$, respectively.

\section{Acknowledgements}

This work was supported by CONACyT project 254280 . 


\section{Conflicts of Interest}

The authors declare no conflicts of interest regarding the publication of this paper.

\section{References}

[1] Tiwari, A. and Dhoble, S.J. (2016) Stabilization of ZnS Nanoparticles by Polymeric Matrices: Syntheses, Optical Properties and Recent Applications. RSC Advances, 6, 64400-64420. https://doi.org/10.1039/C6RA13108E

[2] Jabeen, U., Adhikari, T., Shah, S.M., Pathak, D., Kumar, V., Nunzi, J.-M., Aamir, M. and Mushtaq, A. (2019) Synthesis, Characterization and Photovoltaic Applications of Noble Metal-Doped ZnS Quantum Dots. Chinese Journal of Physics, 58, 348-362. https://doi.org/10.1016/j.cjph.2019.01.012

[3] Nayak, D. and Choudhary, R.B. (2019) Augmented Optical and Electrical Properties of PMMA-ZnS Nanocomposites as Emissive Layer for OLED Applications. Optical Materials, 91, 470-481. https://doi.org/10.1016/j.optmat.2019.03.040

[4] Wang, X., Shi, J., Feng, Z., Li, M. and Li, C. (2011) Visible Emission Characteristics from Different Defects of ZnS Nanocrystals. Physical Chemistry Chemical Physics, 13, 4715-4723. https://doi.org/10.1039/c0cp01620a

[5] Gaikwad, A.P., Betty, C.A., et al. (2018) Microflowers of Pd Doped ZnS for Visible Light Photocatalytic and Photoelectrochemical Applications. Materials Science in Semiconductor Processing, 86, 139-145. https://doi.org/10.1016/j.mssp.2018.05.020

[6] Nam, N.H. and Luong, N.H. (2019) Chapter 7 Nanoparticles: Synthesis and Applications. In: Grumezescu, V. and Grumezescu, A.M., Eds., Materials for Biomedical Engineering, Elsevier, Amsterdam, 211-240. https://doi.org/10.1016/B978-0-08-102814-8.00008-1

[7] Duan, H., Wang, D. and Li, Y. (2015) Green Chemistry for Nanoparticle Synthesis. Chemical Society Reviews, 44, 5778-5792. https://doi.org/10.1039/C4CS00363B

[8] Lee, J., Ham, S., Choi, D. and Jang, D.-J. (2018) Facile Fabrication of Porous ZnS Nanostructures with a Controlled Amount of S Vacancies for Enhanced Photocatalytic Performances. Nanoscale, 10, 14254-14263. https://doi.org/10.1039/C8NR02936A

[9] Akhtar, M.S., Riaz, S. and Naseem, S. (2015) Optical Properties of Sol-Gel Deposited ZnS Thin Films: Spectroscopic Ellipsometry. Materials Today: Proceedings, 2, 5497-5503. https://doi.org/10.1016/j.matpr.2015.11.076

[10] Chen, F., Cao, Y., Jia, D. and Liu, A. (2015) Solid-State Synthesis of ZnS/Graphene Nanocomposites with Enhanced Photocatalytic Activity. Dyes and Pigments, 120, 8-14. https://doi.org/10.1016/j.dyepig.2015.03.030

[11] Feldmann, C. (2005) Polyol-Mediated Synthesis of Nanoscale Functional Materials. Solid State Sciences, 7, 868-873. https://doi.org/10.1016/j.solidstatesciences.2005.01.018

[12] Feldmann, C. and Metzmacher, C. (2001) Polyol Mediated Synthesis of Nanoscale MS Particles ( $\mathrm{M}=\mathrm{Zn}, \mathrm{Cd}, \mathrm{Hg})$. Journal of Materials Chemistry, 11, 2603-2606. https://doi.org/10.1039/b103167h

[13] Chaguetmi, S., Chaperman, L., Nowak, S., Schaming, D., Lau-Truong, S., Decorse, P., Beaunier, P., Costentin, C., Mammeri, F., Achour, S. and Ammar, S. (2018) Photoelectrochemical Properties of $\mathrm{ZnS}$ - and CdS- $\mathrm{TiO}_{2}$ Nanostructured Photocatalysts: Aqueous Sulfidation as a Smart Route to Improve Catalyst Stability. Journal of 
Photochemistry and Photobiology A: Chemistry, 356, 489-501. https://doi.org/10.1016/j.jphotochem.2018.01.038

[14] Ashwini, K., Yashaswini and Pandurangappa, C. (2014) Solvothermal Synthesis, Characterization and Photoluminescence Studies of ZnS:Eu Nanocrystals. Optical Materials, 37, 537-542. https://doi.org/10.1016/j.optmat.2014.07.019

[15] Manivannan, N., et al. (2017) Effect of Gd Doping on Structural, Surface and Optical Properties of ZnS Prepared by Chemical Precipitation Method. Optik, 136, 259-264. https://doi.org/10.1016/j.ijleo.2017.02.050

[16] Asfora, V.K., de Barros, V.S.M., da Silva, R.J.G., Vasconcelos, D.A.A., Nobre, B.S., Yamato, M.E., Khoury, H.J., Oliveira, R.A. and Azevedo, W.M. (2016) Optically Stimulated Luminescence of CaF2:Tm. Radiation Measurements, 85, 73-77. https://doi.org/10.1016/j.radmeas.2015.12.012 